OPEN ACCESS (C) (1) (2)

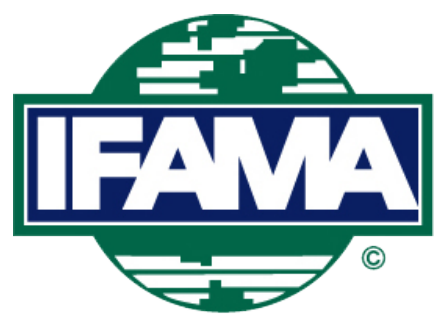

International Food and Agribusiness Management Review

Volume 23, Issue 2, 2020; DOI: 10.22434/IFAMR2019.0037

Received: 21 March 2019 / Accepted: 22 May 2019

\title{
Chinese consumers' willingness to pay for organic foods: a conceptual review REVIEW ARTICLE
}

\author{
Rui Li ${ }^{\oplus a, b}$, Chien-Hsing Lee ${ }^{\mathrm{c}}$, Yu-Ting Lin ${ }^{\mathrm{d}}$ and Chi-Wei Liu ${ }^{\mathrm{e}}$ \\ ${ }^{a}$ Associate Professor, Department of Food Quality and Safety, FoShan University, XianXi \\ Lakeside, DaLi, NanHai District, Foshan, Guangdong 528231, China P.R. \\ ${ }^{b}$ Associate Professor, South China Food Safety Research Center, Guang Dong Province, China P.R. \\ ${ }^{c}$ Assistant Professor, Department of Business Administration, Cheng Shiu University, Kaohsiung 83347, Taiwan \\ ${ }^{d}$ Assistant Professor, Department of Food \& Beverage Management, \\ Cheng Shiu University, Kaohsiung 83347, Taiwan
}

${ }^{e}$ Graduate student, Graduate Institute of Management, Cheng Shiu University, Kaohsiung 83347, Taiwan

\begin{abstract}
China has become one of the largest food markets in the world. Alone with its rising market power, we conceptually review relevant literature to discuss important issues on Chinese consumers' willingness to pay for organic foods. Important factors that might determine consumer willingness to pay were discussed (i.e. culture, demography, attitudinal factors, health consciousness, individual norms, consumer knowledge, food safety, environmental concern, animal welfare, purchasing power, nutritional value). We then put forward a prospect of the future research on consumers' willingness to pay for organic foods in China and other developing countries. Practical and policy implications are also elaborated.
\end{abstract}

Keywords: willingness to pay, Chinese consumers, organic foods JEL code: M31, M37

\footnotetext{
(i)Corresponding author: lirui7533967@outlook.com
} 


\section{Introduction}

'Organic' is a term that refers to the manner that agriculture product is grown and processed, and the regulation and policies governing this process are different from country to country. For instance, in the United States, organic crops must be grown without the use of synthetic pesticides, petroleum-based fertilizers, bioengineered genes (GMOs), and sewage sludge-based fertilizers. Additionally, organic livestock should have access to outdoor and be fed with organic feeds. In the recent past, there has been a massive growth in food safety and environmental sustainability, which has prompted enormous growth of organic agriculture. This urge in safety has seen thousands of hectares been converted to enhance organic production. Demand for organic food is increasing globally, especially in developed countries. For instance, the demand for global organic sales in 2012 was estimated to be $\$ 64$ billion, and over $80 \%$ of these sales mainly in America and European countries (Willer and Lernoud, 2014).

In comparison to other major world economies, China joined the international organic movement late but with a strong potential. The government realized the increasing opportunities for healthy food internationally as well as the domestic product. In this regard, the government is perceived to be in full support of organic agriculture since 2015 as it signed its first bilateral organic certification agreement with New Zealand. Additionally, the Chinese government has incorporated the organic industry into the 'National Plan for the Construction of Ecological civilization'. In this regard, Sternfeld (2009) argues that 'China's organic food development cannot be analyzed without taking into account the fast development of organic food industries in industrialized countries during the past decade.'

Not just knowing about the importance, or just chasing a trend for organic foods, it is indeed critical to know how organic food consumption is in China, because of the environmental and public health challenges encountered in recent years. The main hindrance has been argued to be a paradox between scarcity of arable land and the huge population in the country. Doubt on China's environmental quality and food safety also decline the strength of support to major levels production of organic foods. This is the reason why in recent years there has been an enormous accumulation of public complaints regarding environmental pollution, food poisoning, diseases and death of farmers that heavily use agrochemicals. The food export in the country was also rejected by various countries because of the worry that they contain excessive chemical residues, especially that China was leading in agrochemical farming in the world.

Thus, the organic food imperatives in China become very important, and an interesting area of study on the consumers' willingness to pay for organic foods has emerged. The increase in consumer's concern about food safety and food quality is mainly necessitated by the recent scientific discoveries. However, a majority of these scientific and economic variables associated with food quality and safety are difficult to measure. Therefore, the best technique to ascertain the benefit of a given improvement in food quality and food safety is the estimation of consumers' willingness to pay for organic foods. Generally, the willingness to pay a premium price decreases as the premium increases, which is consistent with the law of demand. The theory of consumer behaviors, however, indicates that consumers make their own decisions to balance the marginal health utility and marginal price of one unit of quality-food products. The willingness to pay can be assessed through consumer behavior towards food products, and this comprises of the willingness to pay a premium price. Organic foods are essential in the consumers' willingness to pay more for the product. The framework is an illustration of the factors that affect organic consumer attitudes and purchase decision.

The 'Green Revolution' saw China heavily rely on agrochemical farming and this resulted in negative health implications. Since then there has been immense sensitization on the importance of organic foods from a health perspective. However, the main challenge is that organic foods are more expensive as compared to the agrochemical foods. The fact that Chinese consumable income and disposable income is not as impressive as that of developed countries, there is a dilemmatic concern on whether Chinese consumers are willing to pay for organic foods. This is taking into consideration the health benefits and the cost implications. Moreover, although other food production economies in Asia such as the Philippines also has potential to 
be researched in this topic, China has greater impact because of the volume and diversity of organic food consumption. Therefore, the purpose of this study is to offer in-depth review on which factors influence the Chinese consumers to be willing to purchase organic foods, based on the knowledge generated by the extant literature.

\section{Theoretical foundation and literature review}

\subsection{Theoretical foundation}

The consumer willingness to pay is mainly a concept that is influenced by the theories that inform studies related to consumer behavior. The primary theoretical framework that can be contextualized is the Theory of Planned Behavior (Ajzen, 1991). The theory suggests that an individual's intention to perform a behavior that is mainly influenced by a conglomeration of behavioral attitudes, subjective norms, and behavioral control. Behavioral attitudes refer to the individual's belief regarding the desirability of behaviors. Subjective norms are the individual's perceived significance of other opinions that are important. Finally, behavioral control is the individual's sense of control over behavior.

\section{- Behavioral attitudes}

An individual's attitude towards consuming a product is one of the most significant antecedents that can be used to predict and explain consumers' choices across product and services, and this includes food products (Honkanen et al., 2006). Attitude is defined as a psychological construct that represent an individual's readiness to act or react in a particular manner (Jung, 1970). It is a process, whereby the individual relatively endures evaluation of an object against alternatives, and this implies that it depends on the cognitive, belief, and emotion of that person towards the object (Dossey et al., 2009). There are some previous studies that have associated organic food consumption with behavioral attitudes such as environmental consciousness, health consciousness, a trust of organic food claims and desirability of organic food attributes such as taste and freshness (Aryal et al., 2009; Gil and Soler, 2006; Hughner et al., 2007). The fact that organic food has been argued to be healthier, safer, and nutritious, the persons that are more health conscious have the propensity to purchase the food.

Trust is defined as confidence in one's expectation, whereby desirable conducts are perceived in a certain manner while those that are not desirable are not considered. Trust that is associated with organic food claim is very vital, and it is a determinant of intention to consume because of the credibility of organic food. The major aspects that influence trust are advertisement, packaging, labeling, and certification symbols.

\section{- Subjective norms}

Subjective norm is described as the perceived social pressure to undertake or not to undertake a behavior (Ajzen, 1991; O’Neal, 2007). People's subjective norm reflects their belief about how others would view them engaging in a particular behavior. In this regard, McClelland's (1987) theory of needs suggests that people are likely to engage to perform the behavior that is perceived desirable by loved ones of referent group because of their need for affiliation and group identification. Therefore, it is likely that individual 's intention to consume organic food would be influenced if they believe that their loved ones expect to do so, or they want to be identified with individuals that consume organic food (Chen, 2007).

\section{- Behavioral control}

Perceived behavioral control concerns individuals' perception on the extent they are able to perform a given behavior (Ajzen, 1991). Underlying such perception is their belief regarding the relative difficulty or ease in performing that behavior as well the extent to which that performance is up to them. In a situation where the performance of a behavior is perceived to be easy and within the ability of the individual, the intention 
to perform the behavior is strengthened. There are some studies that have assessed this phenomenon and have operationalized affordability as a subset of behavioral control, in influencing behavioral intention (Oh and Hsu, 2001; Thompson and Thompson, 1996). Affordability is one of the aspects that is associated with behavioral control, and for consumers' affordability it is mainly linked with monetary and search. This is the main reason why some studies indicate that a higher monetary cost is perceived as the main barrier to organic food consumption (ACNielsen, 2015).

\subsection{Organic food in China}

Organic agriculture has not become popular in China until the mid-20 $0^{\text {th }}$ century. The practice of organic agriculture was prevalent in rural areas where farmers were too poor to afford agrochemicals. However, these agricultural practices changed during the past 60 years. In the early 1970s, there was a phenomenon that was called the 'Green Revolution,' which meant agricultural mechanization, the introduction of hybrid crops, improved irrigation, and elevated input of agrochemicals. These were very vital as they increased food production that was needed to feed the Chinese population which was increasing exponentially. The authoritarian government of China would not take positively any critics that opposed this move, and there are some incidences that saw people been jailed for opposing the 'Green Revolution'. Studies indicate that today China is the world leading user of chemical fertilizers, whereby the Chinese farmers apply about $33 \%$ of the global production of nitrogen fertilizers. With such massive production of agrochemical products, it comes very vital to investigate consumers' willingness to purchase organic agricultural given the fact that they are more expensive.

In recent times there has been a remarkable growth in demand for organic food in China. This is due to the fact that income increases and consumers tend to have the tendency of consuming high quality food (Tian and $\mathrm{Yu}, 2013)$.

The 'Green Food' is classified into two: the 'A' grade which represents a transitional level between conventional and organic foods, and it permits restricted use of chemical fertilizers and pesticides, then the 'AA' category that represents 'Green Food' that has attained fully organic status. Some studies have ascertained that majority of the food sold in the domestic market is the 'A' standard and not the 'AA' standard (Sanders, 2006). The Chinese certified organic label was developed by the Organic Food Development Centre, and it is more concerned with the export market (Paull, 2008). Previous studies have indicated that certified organic food products only account for $0.08 \%$ of all the total foods consumed in China (Yin et al., 2010) and the fact that China is an emerging economy, price is a major barrier in purchasing these certified foods (Paull, 2008). The organic labels compete strongly with the green food label in terms of image, and positioning in the market, and this brings confusion (Marchesini et al., 2012).

The market for the premium organic food has been rapid in China, and opportunities for organic food market is promising for exporters and food supplement suppliers. The main driver of Chinese organic food production has been argued to be trade-related, which is mainly associated with growing demand for organic product on the global market (Kledal et al., 2007). There is numerous rationale for the 'greening' of agriculture, such as problems with environmental pollution, maintenance of healthy population, problems with environmental pollution, necessity to raise income of farmers, and the need to increase the image of China-produced food in the international market and overcome the called 'green barrier' in international markets (Paull, 2008).

Larranga (2013) indicates that the demand for organic produce in China is mainly estimated to exceed the world average because of several reasons. The first is concerned with food safety issues, and this implies that the demand for organic/green food is driven by acute lack of confidence in the safety and quality of Chinese produce (Morgan and Wright, 2014). This is after the 2008 incident that eroded the public confidence in the authorities to guarantee food safety. The issue revealed that there was a major quality control problem in the country (Geng et al., 2013). The second aspect is that there has been significant growth of the middle class, and this has resulted to an emergence of a niche market for high-quality food, and consumers have the 
money to pay for that price (Sun and Mu, 2012; Zhang and Han, 2009; Zhong and Yi, 2010). Finally, there has been an increase in sales channels, and this has elevated the number of dedicated organic food stores in both domestic and international supermarkets (Sheng et al., 2009).

Despite the vast literature on organic food consumption, on who buys and the reason why they buy, there is very little known about organic food consumption in China. One qualitative study found that Chinese consumers perceive organic food as healthy and safe but costly (Marchesini et al., 2012). Another exploratory study indicated that Chinese consumers are driven less by altruistic motivations such as animal welfare, support for small scale farmers and environmental preservation as compare to individualistic motivations (Sirieix et al., 2011). The major reason that they consider organic foods is because of health concerns, people are worried about the chemical present in the conventional foods. Another exploratory study on the factors that influence organic food consumption revealed that health concerns, degree of trust in the organic food regarding the pricing, their income, were argued to be a major aspect that influence motivation to purchase organic foods (Yin et al., 2010). However, Thøgersen and Zhou (2012) indicated that Chinese consumers are not different for the rest of the world's consumers, which means that they are influenced by the same factors value priorities and beliefs. This include aspects such as perceptions on health, residue in the agrochemicals, taste, and the environmental implications influence their purchase decisions. Chinese studies indicate that gender, age, family size and household income are the major socio-economic factors that influence the willingness to purchase green food (Xia and Zeng, 2007, 2008). China is an emerging market, and there are some previous that argue that demographics do not distinguish between buyers of organic and conventional products (Lockie et al., 2004; Pearson et al., 2013). Therefore, there might be some challenges in using demographics in China to determine whether variables of demographics influence the willingness to purchase in China.

Food safety and sustainability are two important determinants that are considered in food quality, and this is the reason why 'Green Food' has become popular in China since it has fewer chemical residues. The development of 'Green Food' and organic food rationale is that organic food has the propensity of enhancing environmental sustainability of agriculture as well as reduction of food-borne diseases and elevating farmers' income in China (Sanders, 2006; Sirieix et al., 2011; Yang et al., 2014; Yin et al., 2010). Since the initiation of 'Green Food' in 1989, both the numbers of certified firms and the certified products have increased, and it can be argued that the 'Green Food' in China is at a mature level. It is approximated that in 2012 there were over 2,600 certified firms in China and 6,862 products. Yu et al. (2014) indicate that the increase in 'Green Food' certification is consequential since it has a direct impact on the agricultural land use in China. There is in immense increase in land use for the production of 'Green Food' in China, and this is an indication that producers are accepting this practice immensely. Despite the fact that consumers' attitudes towards 'Green Food' in China are not well researched, there are numerous studies that have been conducted on preference for organic food in different countries and their results can be used to determine consumers' willingness to purchase organic food in China.

\subsection{Consumers' willingness to pay for organic foods}

The fact that the demand for organic products have greatly increased, has resulted in the subject has received much attention on consumer choice literature. Various scholars have used different techniques and methodologies to investigate consumer willingness to purchase organic food. One of the techniques used is contingent valuation surveys, whereby hypothetical markets are set up in which consumers' willingness to pay for the products are solicited by asking respondents to value the products contingent on the available market. In many occasions, market prices are already existing, and contingent valuation surveys tend to focus on the premiums that consumers are more willing to pay for that product. There are some contingent surveys that have only used the single-bounded approach, whereby individuals are offered only in a bid to either pay or reject (Haghiri et al., 2009). The double-bounded approach is mainly used where there is massive need to value non-markets good as more information regarding individual's willingness to pay is considered. Moreover, such a study has a propensity to provide more efficient estimates as well as tighter 
confidence intervals (Hanemann et al., 1991). Misra et al. (1991) and Boccaletti and Nardella (2000) are examples of studies that used contingent valuation and analysis to assess consumers' willingness to pay for pesticides-free fruits and vegetables in Italy and the USA. Moreover, Gil et al. (2000) used contingent valuation, and concluded that consumer willingness to pay more for organic foods in Spain is very high.

The other approach that has been used to investigate consumers' willingness to pay for organic foods is the choice experiment (CE). The only disadvantage of this technique is that attributes of food quality are assumed to be independent of attributes that are not provided to respondents in the survey or experiment (Gao and Schroeder, 2009). A study by Stolz (2011) that employed latent class models ascertained that consumers who strongly prefer organic products are less price sensitive as compared to those that prefer conventional products.

The third common form found in the literature is the hedonic pricing methodology that imputes prices of attributes based on the relationship between the observed prices of differentiated products and the number of attributes that are linked with these products. Nonetheless, there is limited provision on the choice of proper functional form and this has been argued to lead to inconsistent estimates. Such a study of hedonic pricing is of Nouhoheflin et al. (2004) that aimed to indirectly use valuation to investigate consumer perception and willingness to pay high prices for organic vegetables compared to conventional vegetables in Ghana. The empirical study suggested that consumers were willing to pay more than $50 \%$ premium for vegetables that were chemical free.

Empirical literature on consumer surveys suggest that consumers' socio-economic characteristics such as gender, age, level of education, household size and income level as well as the level of consumers' awareness and perception, size, freshness, taste and cleanness have the propensity of influencing consumers' willingness to pay for organic food products. Govindasamy and Italia (2006) indicated that younger consumers regardless of gender paid higher premiums for organic products. Additionally, Liu et al. (2009) found an Inverted-Ushape relationship between age and consumer willingness to pay and suggested that willingness to pay for additive free food increases with age but decreases as age increases to a particular limit. However, Darby et al. (2008) revealed that there is significant impact of age on consumers' willingness to pay. There are numerous studies that have indicated that females are more willing to pay more premiums for safe foods such as organic foods as compared to their male counterpart. Other statistical studies have indicated that willingness to pay is highly correlated to education (Darby et al., 2008; Liu et al., 2009).

However, there seem to be no consensus on the effect of consumers' willingness to pay for safe foods. The fact that consumers' willingness to pay for safe food is negatively correlated with marginal utility of money, it is expected that consumers' willingness to pay is expected to increase as the income of the consumer increases (Liu et al., 2009). Some studies have indicated that there is no significant relationship that income determines willingness to pay for organic food products (Darby et al., 2008). Moreover, there are some studies that indicate that consumers' cognition of food safety has a positive impact on willingness to pay (Darby et al., 2008; Liu et al., 2009). There are also some empirical studies that have indicated that consumers are more likely to develop positive attitudes towards the health enhancing attributes of organic food, such as nutrition and safety compared to conventionally produced food (Michaelidou and Hassan, 2008).

\section{Factors influencing the willingness to pay of organic food in China}

\subsection{Cultural perspectives of food in China}

Zhou (2008) indicates that food has been part of an intrinsic Chinese value, and it is an embodiment of the Chinese culture that has been deeply entrenched in the Chinese society for thousands of years. Therefore, it is an essential part in the life of Chinese consumers. Comprehension of the importance linked to the consumption of food provides a valuable of gaining a vivid understanding of the Chinese culture (Eves and Cheng, 2007). In China, the three categories of food that are argued to be safe, environmentally friendly, and 
ecological correct are termed as 'non-polluted food' (or hazard free-free food), 'green food' and 'organic food' (Chen et al., 2014). Various studies have explained and classified these categories, whereby the lowest level is non-polluted food and the highest is organic food (Gao et al., 2009). The fact that China is one of the largest organic market in the world (Zhou, 2008), international retailers such as Walmart and Carrefour have found the organic market in China very lucrative. This is despite the fact that studies have indicated that consumers in China have found organic foods very expensive (Sanders, 2006). Last but not least for the cultural concerns, Chinese agribusiness stakeholders (i.e. farmers, consumers, cooperatives, etc.) often make decisions and act based on their social capital (e.g. Xu et al., 2018). It is also an important cultural concern when it deals with consumer's decisions, especially when purchasing a higher-priced kind of food such as organic food.

Previous studies have suggested that demographic profiles of consumers such as age, gender, education, level of income has a high propensity of influencing their purchase behavior of organic food (Lea and Worsley, 2005; Ureña et al., 2008). Moreover, numerous studies have indicated that food safety is a vital criterion that influences consumers to purchase organic food products (McEachern and McClean, 2002; Rimal et al., 2005; Tsakiridou et al., 2008). Additionally, it has been argued that an increase in the sensitization regarding food safety can affect the attitude towards specific food products. A recent study by Wirth et al. (2011) revealed that food attributes such as texture, flavor, and price are very significant as compared to any other attribute in regard to the preference for organic food by consumers. A previous study by Dahm et al. (2009) in concurrence with this assertion indicates that taste is equally as important as quality, followed in order by price, appearance and availability. There is minimal of literature in relation to Chinese consumers' attitude towards organic food products of their associated purchase behavior. For instance, Yin et al. (2010) asserted that there is no previous study that have explored the consumers' choice of organic food in mainland China market. Their study indicated that consumers' intention to buy organic food is mainly influenced by the level of income, degree of trust and the acceptance of organic food and health concerns.

\subsection{Demography}

Previous studies indicate that gender is an influential demographic variable that can influence the decision of making a choice on the type of organic food to be consumed and purchased. Women have been asserted to be concerned about health, nourishment and environment, and that they are more prone to have a favorable attitude towards organic food (Chen et al., 2014). The rationale given to this phenomenon is the fact that women have a higher tendency of doing the household shopping as compared to men, and they take more responsibility for the family making to be more aware of organic food (Lockie et al., 2004; Onyango et al., 2007).

In terms of age, it has been argued that younger consumers have a higher tendency to purchase organic food as compared with older consumers. The rationale given to this phenomenon by some studies is that older consumers have limited disposable income. Education is another demographic variable that influences the willingness to purchase organic food. Consumers with higher education levels are more willing to pay more for organic food because education influences the perception of a healthy diet (Tsakiridou et al., 2008). Krystallis et al. (2006) indicate that education seems to have converted the unaware consumer into a highly motivated organic supporter and the majority of the educated respondents in their study were more aware of nutrition information. Moreover, higher income and education have higher positive correlation with environmental concern and food safety. This is the reason why Tsakiridou et al. (2008) assert that more organic food consumers are higher income earners, and more often linked to higher education levels.

Whether consumers will purchase organic food is mainly dependent on subjective experiences and perception (Hughner et al., 2007). The main drivers are related to health (Chen, 2009), and the growing concerns that are related to ecological values (Tsakiridou et al., 2008), and this is mainly related to environmental sustainability as well as the hostile impact of conventional agriculture on the environment. There is a prevalent belief that organic food is healthier, more nutritious and safer (Chen, 2009). Therefore, studies have indicated that 
consumers with positive attitudes towards organic food are more likely to have strong intentions to purchase organic foods. Nonetheless, one of the key contentious issue that relate to organic food products is that there is limited convincing scientific evidence that demonstrate their health merits (Brennan et al., 2003).

\subsection{Attitudinal factors}

The attitudes and behavior towards organic food have been considered to have provided immense evidence that they consider health concerns and environmental issues as the most influential aspects that inform the purchase decisions (Chen, 2009). The importance of knowledge of organic foods is an issue that affect purchasing decisions, and this is due to the fact that consumers that have no information cannot differentiate the positive attributes of organic food from the conventional alternatives (Botonaki et al., 2006; Yiridoe et al., 2005). Magistris and Gracia (2008) suggest that consumers with knowledge that organic food is more beneficial from a health perspective, is an aspect that can influence their purchase decision. Moreover, the study also indicted that more information in the organic food market has the propensity of improving consumer's knowledge. Hence, it is very important to enhance organic knowledge among potential consumers in any effort that is meant to improve the market of organic food. Great information regarding organic food markets has been asserted by some studies to develop consumer markets (Hoffmann and Schlicht, 2013), and it also influences their attitudes towards organic food products. Consumers are prone to seek clear, accurate and reliable information regarding organic food, especially labelling. In normal circumstances, they will have seen a logo or a label that defines the organic credentials, and they express a need for more information that is associated with the organic food (Lin et al., 2008). Other studies have indicated that the geographical origin of such organic food products is very influential on whether customers will be willing to pay for the organic food product. Therefore, country of origin has been used as a very powerful component of the promotional mix, and this has been argued to be the fact that organic buyers have the propensity to exhibit a strong ethnocentric tendency. Therefore, this fact will be very vital in this study to determine whether the willingness to pay for organic food in China is dependent on the country of origin of organic food.

\subsection{Other critical factors}

The willingness of the Chinese consumers to pay for organic foods was found to be highly influenced by their perception of the different organic foods. The review of the selected articles revealed that there are various factors that affect or facilitate the consumers' attitude towards organic foods. These factors include:

\section{- Health consciousness}

The belief that organic foods are good for human consumption influences many people to have a positive attitude about the foods. According to Yang, Al-Shaaban and Nguyen (Yang et al., 2014), a positive attitude towards organic foods is derived from the fact that consumers can consume the foods without fear of consuming chemicals, pesticides and other chemicals that are harmful for human consumption. Xie et al. (2015) also noted that Chinese consumers who believe that organic foods are good for health have positive attitudes towards consumption of such foods. The results of this analysis are consistent with those reported by Li and Xin (2015) and Zhu (2018).

\section{- Individual norms}

The influence of individual norms on the attitude of the consumers towards organic foods is determined by the extent to which individuals perceive their actions to be right or wrong. In this case, the positive attitude towards organic foods is based on personal choices where consumers feel that the consumption of organic foods is the right thing to do, compared to the mainstream foods. According to Yen (2017), consumers are more inclined to consume organic foods when such consumptions are aligned with their self-image, self-reflection and similar people purchasing organic foods. Consistent findings were reported by a study 
conducted by Yang et al. (2014) which reported that individual norms had major impacts on a Chinese consumer's attitude towards organic foods.

\section{- Consumer knowledge}

The influence of consumer knowledge on the attitudes towards organic foods is a dominant theme in this analysis. Liu et al. (2013) explain that despite the fact that the Chinese consumers are presented with information about food safety and the concept of organic foods, there is generally a low level of recognition of the concept of safe foods, including labels and identification of safe foods. Gan et al. (2014) also suggest that most Chinese consumers would prefer organic foods if they had enough information to base their purchase decisions. According to a study conducted by Xie et al. (2015), the consumer knowledge factor was critical in influencing the attitudes of the people towards the consumption of organic foods, citing that lack of awareness and knowledge about the benefits of organic foods is a major barrier to willingness to purchase organic foods in China

\section{- Food safety}

With many Chinese food scandals bombarding the Chinese consumers, many of them are increasingly looking for safe foods that are free from contaminants, chemicals or other types of toxins (Gan et al., 2014). The young consumers are especially more motivated to purchase organic fruits and vegetables as opposed to the conventional fruits and vegetables.

\section{- Environmental concern}

Consumers have become a major force in promoting the consumption of foods that are more protective of the environment and companies that produce foods aligned with future sustainability. Li and Xin (2015) notes that the majority of the Chinese consumers have positive attitudes towards organic foods because they are environment-friendly and their production do not involve the pollution of the environment. Zhu (2018) recommends that organic foods marketers should connect the marketing of organic foods with environmental values in order to promote a higher level of consumption of organic foods in the country. McCarthy (2015) noted that Chinese consumers have a positive attitude towards organic foods based on the perception that such consumptions are good for the welfare of the animals. Moreover, this factor is related to the environmental consideration and food safety, as most of the animals consumed for foods are not grown using chemicals that are used to speed up the growth process. Gan et al. (2014) also notes that the value of organic foods is also connected to the heightened concern for animal rights. These findings are consistent with the results of the study conducted by McCarthy (2015) who linked organic foods consumption to animal welfare concerns.

\section{- Purchasing power}

The level of consumption foods in China is positively correlated to the income levels of the consumers. Despite the fact that most consumers may be aware of the health benefits of consuming organic foods, they do not purchase them because they are expensive compared to conventional foods that are cheaper and readily available (Gan et al., 2014). Evidence also demonstrate that there is a high demand for organic foods among higher food expense consumers as they are willing to pay a premium for the food.

\section{- Nutritional value}

The nutritional value of organic foods is a major motivation that has a positive impact in influencing consumption patterns. According to Li and Xin (2015), organic foods have favorable nutritional ingredients that promote positive attitudes. Moreover, organic foods are reported to taste and smell better than the majority of conventional foods. With many people becoming conscious of their health and lifestyle choices, the demand for organic foods increases as they are considered a healthier and more nutritious alternative 
(Gan et al., 2014). Xie et al. (2015) also reported organic foods as healthier and nutritious, hence eliciting high demand especially among older people who are becoming more and more conscious of their health.

\section{Summary and future research}

From this research, it is evident that there are numerous factors that should be considered as they have the propensity of driving consumers' perceptions and attitudes towards organic food in China. These factors and perceptions should be greatly considered when rolling out organic foods in China whether in the rural open markets or retail outlets. The fact that the market of organic food is experiencing rapid development in China, makes this study very important to the agricultural stakeholders that are mainly keen on the organic foods. The main aspect that can be deduced form the study in regard to influencing the Chinese consumer to purchase organic food is on health, and this is due to the past food incidents that have been consequential on the Chinese people. Therefore, this is the reason why the health consciousness of Chinese people together with food safety issues and the industrialization process surrounded by chemicals has made more consumers to seek for organic foods.

The willingness to pay for organic food in China is dependent on the costs of such food. Despite the positive perception regarding the benefits that is accrued as result of consuming organic food, price remain a major hindrance. As indicated in the study the willingness to pay a premium price decreases as the premium increases, which is consistent with the law of demand. The theory of consumer behavior indicates that consumers make their own decisions to balance the marginal health utility and marginal price of one unit of quality-food products. Comparing China's economic indicators with developed countries such as those in Western Europe and North America, aspects such as disposable income in China is minimal and consumers might tend to be hesitant to purchase organic food. However, as indicated in the study willingness to pay is influenced by three main aspects; knowledge, attitude, and intention. All these three aspects can be contextualized to influence the potential consumers in China to purchase organic food despite the price factor. Knowledge about the product is very vital as it influences the willingness to pay for the product. Knowledge is mainly affected by the type of information that is presented to the consumers. The information can be communicated through advertisements, the quality of packaging, labeling, and certification familiar to the consumers. After the potential consumer is ready to purchase the product, the next vital step is to determine how much she is willing to pay for the product, which is the intention. For instance, knowledge about the health benefits that are associated with organic food can influence the consumer to purchase the organic foods. This knowledge regarding the health and nutritional benefits is gotten through distribution of information such as advertisement and health sensitization programs. Thereafter, the customer decides on whether to purchase that organic product or not. Therefore, the behavior of a consumer to either purchase the organic product is determined by these three aspects. The assertion deduced from the study can be argued to be applicable to Chinese consumers, since they are no different from other consumers across the globe. However, the only aspect that should be considered is the economic perspective of China as a country. The fact that price is an element embedded in economics, makes it very vital to assess the economics perspective of China.

The price (cost) that is required to be paid for this organic food is too high for a majority of the population in China. Therefore, there should be a holistic approach on the price that should be considered to ensure that the price of organic food is more affordable. Therefore, one of the recommendations that is suggested by this paper is reducing the cost of organic food through multiple channels as this might decrease the market price. Moreover, there should be enough support for organic food producers in terms of technological innovation. This will be vital in increasing organic food produce, and reduction of cost of production. The government and other agricultural agencies should also ensure that brand building of organic food and organic food products is achieved as a means of reducing the production costs and risks, which in the long run will reduce the price of organic food at the source.

It is also recommendable that expansion of consumers direct markets should be encouraged in China, as this, from an economical perspective, would reduce the market price of organic food in the country. Measures 
such as reinforcing the combination of producers, standardizing certification procedures and enhancing certification efficacy can be considered by the relevant agencies as a means of reducing certification costs of organic foods that raises the price. There is no doubt that the future of organic foods in China is promising, however it is not certain on when or to what extent that consumers in China will become regular consumers for organic foods. However, increasing the awareness regarding organic farming and the benefits accrued as result of consuming organic foods is very vital as it will guarantee an increased market share of organic foods.

The only way to ensure that the market share of organic food will increase, is to increase the production to match that of conventional foods. There are studies that have indicated that it is more possible to increase production of organic agriculture through best agricultural practices and innovations. The environmental benefits of organic agriculture are enormous despite the low yields as compared to conventional foods. Some of the sustainability measures that should be adopted include aspects such as biodiversity preservation, soil fertility building and reduction of nitrogen losses. However, there are some farming techniques that should be avoided such as rotational farming, multi-crop farming, cover cropping, and polyculture because they have the propensity of reducing land use in organic farming. Innovation on how to increase the production of organic food through organic agriculture should be the center of attention. Future strategies should prioritize productivity increase that is mainly concerned with organic farms as well as ensuring that there is a positive ecological performance that organic agriculture can provide. This is because, as ascertained in the study, the prices of organic products are a major hindrance to consumers' willingness to purchase organic foods either in China or other emerging markets such as those located in South Asia, Mid-and-South America, and Africa. Consumption foods in China is positively correlated to the income levels of the consumers. Hence, increasing the level of production will increase the supply organic food in the market and this will help in reducing the price. Therefore, the study is very important for agencies that are planning to enhance and increase production of organic food. They should find this study very vital as it gives the factors that influence consumer's willingness to pay for organic food and the mechanism that can be adopted to increase this behavior. Finally, we only focused on the discussion of the factors proposed as they function independently. However, there are some situations where these factors are interrelated when functioning. Future studies are suggested to investigate such interrelatedness of important factors influencing consumers' willingness to pay for organic foods in China and other emerging economies.

\section{Acknowledgements}

This study was partially supported by the Guangdong province Characteristic innovation in University Fund's project: 'Structure-conduct-performance' Model of Community supported Agriculture in Guangdong province in China. Additionally, Humanities and Social Sciences Research in the Ministry of Education, and Youth Fund Projects in the Border Areas. Funding for the collaborative path research for poverty alleviation (15XJC840002) is acknowledged. Also, this study was subject to the National Social Science Fund's general project 'Study on the Synergistic Path of Tourism Accurate Poverty Alleviation and Traditional Village Rejuvenation in Ethnic Areas' (16BSH028).

\section{Conflicts of interest}

The authors declare no conflict of interest.

\section{References}

ACNielsen. 2015. Organic and functional foods have plenty of room to grow according to new ACNielsen global study. Available at: https://www.businesswire.com/news/home/20051205005956/en/OrganicFunctional-Foods-Plenty-Room-Grow-New

Ajzen, I. 1991. The theory of planned behavior. Organizational Behavior and Human Decision Processes 50(2): 179-211. https://doi.org/10.1016/0749-5978(91)90020-T 
Aryal, K., P. Chaudhary, S. Pandit and G. Sharma. 2009. Consumers' willingness to pay for organic products: a case from Kathmandu Valley. Journal of Agriculture and Environment 10: 5. https://doi.org/10.3126/ aej.v10i0.2126

Boccaletti, S. and M. Nardella. 2000. Consumer willingness to pay for pesticide-free fresh fruit and vegetables in Italy. International Food and Agribusiness Management Review 3: 297-310.

Botonaki, A., K. Polymeros, E. Tsakiridou and K. Mattas. 2006. The role of food quality certification on consumers' food choices. British Food Journal 108: 77-89.

Brennan, C., K. Gallagher and M. McEachern. 2003. A review of the 'consumer interest' in organic meat. International Journal of Consumer Studies 27: 381-394.

Chen, J., A. Lobo and N. Rajendran. 2014. Drivers of organic food purchase intentions in mainland China - evaluating potential customers' attitudes, demographics and segmentation. International Journal of Consumer Studies 38(4): 346-356. https://doi.org/10.1111/ijcs. 12095

Chen, M. 2007. Consumer attitudes and purchase intentions in relation to organic foods in Taiwan: moderating effects of food-related personality traits. Food Quality and Preference 18(7): 1008-1021. https://doi. org/10.1016/j.foodqual.2007.04.004

Chen, M.-F. 2009. Attitude toward organic foods among Taiwanese as related to health consciousness, environmental attitudes, and the mediating effects of a healthy lifestyle. British Food Journal 111: $165-178$.

Dahm, M.J., A.V. Samonte and A.R. Shows. 2009. Organic foods: do eco-friendly attitudes predict ecofriendly behaviors? Journal of American College Health 58: 195-202.

Darby, K., Batte, M.T., Ernst, S. and B. Roe. 2008. Decomposing local: a conjoint analysis of locally produced foods. American Journal of Agricultural Economics 90(2): 476-486.

Dossey, B., L. Keegan and C. Barrere. 2009. Holistic nursing: a handbook for practice. Jones and Bartlett Publishers, Sadbury, MA, USA.

Eves, A. and L. Cheng. 2007. Cross-cultural evaluation of factors driving intention to purchase new food products - Beijing, China and South-East England. International Journal of Consumer Studies 31: 410-417.

Gan, C., C. Zhiyou, M.C. Tran, D.A. Cohen and W. Xiangxiang. 2014. Consumer attitudes towards the purchase of organic products in China. Faculty of Agribusiness \& Commerce Working Paper 15. Lincoln University, Lincoln, New Zealand.

Gao, Z. and T.C. Schroeder. 2009. Effects of label information on consumer willingness-to-pay for food attributes. American Journal of Agricultural Economics 91(3): 795-809.

Geng, W., J. Trienekens, E. Wubben and G. Schiefer. 2013. Improving food safety within China's dairy chain: key issues of compliance with QA standards. International Journal on Food System Dynamics 4(2): 117-129. https://doi.org/10.22004/ag.econ.164793

Gil, J. and F. Soler. 2006. Knowledge and willingness to pay for organic food in Spain: evidence from experimental auctions. Food Economics - Acta Agriculturae Scandinavica, Section C 3(3-4): 109124. https://doi.org/10.1080/16507540601127656

Gil, J.M., A. Gracia and M. Sánchez. 2000. Market segmentation and willingness to pay for organic products in Spain. International Food and Agribusiness Management Review 3(2): 207-226.

Govindasamy, R., M. DeCongelio and S. Bhuyan. 2006. An evaluation of consumer willingness to pay for organic produce in the Northeastern U.S. Journal of Food Products Marketing 11: 3-20.

Haghiri, M., J.E. Hobbs and M.L. McNamara. 2009. Assessing consumer preferences for organically grown fresh fruit and vegetables in Eastern New Brunswick. International Food and Agribusiness Management Review 12(4): 81-99.

Hanemann, M.W., J.B. Loomis and B.J. Kanninen. 1991. Statistical efficiency of double-bounded dichotomous choice contingent valuation. American Journal of Agricultural Economics 73: 1255-1263.

Hoffmann, S. and J. Schlicht. 2013. The impact of different types of concernment on the consumption of organic food. International Journal of Consumer Studies 37: 625-633.

Honkanen, P., B. Verplanken and S. Olsen. 2006. Ethical values and motives driving organic food choice. Journal of Consumer Behaviour 5(5): 420-430. https://doi.org/10.1002/cb.190 
Hughner, R., P. McDonagh, A. Prothero, C. Shultz and J. Stanton. 2007. Who are organic food consumers? A compilation and review of why people purchase organic food. Journal of Consumer Behaviour 6(2-3): 94-110. https://doi.org/10.1002/cb.210

Jung, C. 1970. The collected works. Princeton University Press, Princeton, NJ, USA.

Kledal, P., Q. Hui, H. Egelyng, X. Yunguan, N. Halberg and L. Xianjun. 2007. Organic food and farming in China. In: Willer, H. and M. Yussefi (eds.) The world of organic agriculture - statistics and emerging trends 2007. IFOAM - Organics International/FiBL, Bonn/Frick, Germany/Switzerland, pp. 114-119.

Krystallis, A., C. Fotopoulos and Y. Zotos. 2006. Organic consumers' profile and their willingness to pay for selected organic food products in Greece. Journal of International Consumer Marketing 19: 101-106.

Larranga, J. 2013. Exporting organic to China. Australian Organic News, August 2013. Available at: https:// austorganic.wordpress.com/2013/08/06/exporting-organic-to-china/

Lea, E. and T. Worsley. 2005. Australians' organic food beliefs, demographics and values. British Food Journal 107: 855-869.

Li, X. and Y. Xin. 2015. Factors influencing organic food purchase of young Chinese consumers. MSc-thesis, Uppsala University, Uppsala, Sweden.

Lin, B.-H., T.A. Smith and C.L. Huang. 2008. Organic premiums of US fresh produce. Renewable Agriculture and Food Systems 23: 208-216.

Liu, R., Z. Pieniak and W. Verbeke. 2013. Consumers' attitudes and behaviour towards safe food in China: a review. Food Control 33(1): 93-104.

Liu, Y., Y. Zeng and X. Yu. 2009. Consumer willingness to pay for food safety in Beijing: case study of food additives. Contributed paper prepared for presentation at the International Association of Agricultural Economists Conference. August 16-22, 2009. Beijing, China P.R., pp. 6-15.

Lockie, S., K. Lyons, G. Lawrence and J. Grice. 2004. Choosing organics: a path analysis of factors underlying the selection of organic food among Australian consumers. Appetite 43: 135-146.

Magistris, T.D. and A. Gracia. 2008. The decision to buy organic food products in Southern Italy. British Food Journal 110: 929-947.

Marchesini, S., H. Huliyeti and M. Canavari. 2012. Perceptual maps analysis for organic food consumers in China: a study on Shanghai consumers. University of Bologna, Bologna, Italy. https://doi.org/10.6092/ unibo/amsdottorato/2080

McCarthy, B.L. 2015. Trends in organic and green food consumption in China: opportunities and challenges for regional Australian exporters. Journal of Economic \& Social Policy 17(1): 6.

McClelland, D.C. 1987. Human motivation. Cambridge University Press, New York, NY, USA.

McEachern, M.G. and P. McClean. 2002. Organic purchasing motivations and attitudes: are they ethical? International Journal of Consumer Studies 26: 85-92.

Michaelidou, N. and L.M. Hassan. 2008. The role of health consciousness, food safety concern and ethical identity on attitudes and intentions towards organic food. International Journal of Consumer Studies 32(1): 163-170.

Misra, S.K., C.L. Huang and S.L. Ott. 1991. Consumer willingness to pay pesticide-free fresh produce. Western Journal of Agricultural Economics 16: 218-227.

Morgan, B. and C. Wright. 2014. The market opportunities for Australian vegetables in China. AUSVEG National Convention, Cairns Convention Centre. June 19-21, 2014. Available at: https://ausveg.com. au/app/uploads/technical-insights/pdf_file_4243.pdf

Nouhoheflin, T., O. Coulibaly, A.J. Cherry, R. Al-Hassan and P.Y. Adegbola. 2004. Consumers 'perception and willingness to pay for organic vegetable in Benin and Ghana. Paper presented at the Inaugural Symposium of the African Association of Agricultural Economists, Nairobi, Kenya.

O'Neal, P.W. 2007. Motivation of health behavior. Nova Science Publishers Inc., New York, NY, USA.

Oh, H. and C. Hsu. 2001. Volitional degrees of gambling behaviors. Annals of Tourism Research 28(3): 618-637. https://doi.org/10.1016/s0160-7383(00)00066-9

Onyango, B.M., W.K. Hallman and A.C. Bellows. 2007. Purchasing organic food in US food systems: a study of attitudes and practice. British Food Journal 109: 399-411.

Paull, J. 2008. China's organic revolution. In: Bhaskaran, S. and S. Mohanty (eds.) Marketing of organic products: global experiences. Icfai University Press, Hyderabad, India, pp. 260-275. 
Pearson, D., J. Henryks. P. Sultan and T. Anisimova. 2013. Organic food consumers: exploring purchase frequency to explain consumer behavior. Journal of Organic Systems 8(2): 50-63.

Rimal, A.P., W. Moon and S. Balasubramanian. 2005. Agrobiotechnology and organic food purchase in the United Kingdom. British Food Journal 107: 84-92.

Sanders, R. 2006. A market road to sustainable agriculture? Ecological agriculture, green food and organic agriculture in China. Development and Change 37(1): 201-226. https://doi.org/10.1111/j.0012155x.2006.00475.X

Sheng, J., L. Shen, Y. Qiao, M. Yu and B. Fan. 2009. Market trends and accreditation systems for organic food in China. Trends in Food Science \& Technology 20(9): 396-401.

Sirieix, L., P. Kledal and T. Sulitang. 2011. Organic food consumers' trade-offs between local or imported, conventional or organic products: a qualitative study in Shanghai. International Journal of Consumer Studies 35: 670-678.

Sternfeld, E. 2009. Organic food 'made in China'. Available at: https://www.eu-china.net/materialien/ organic-food-made-in-china-2/

Stolz, H., M. Stolze, U. Hamm, M. Janssen and E. Ruto. 2011. Consumer attitudes towards organic versus conventional food with specific quality attributes. NJAS - Wageningen Journal of Life Sciences 58(3-4): 67-72.

Sun, Q. and Y. Mu. 2012. Analysis of vegetable consumption features and consumption demand system of Beijing residents. Chinese Agricultural Science Bulletin 28(12): 257-263.

Thøgersen, J. and Y. Zhou. 2012. Chinese consumers' adoption of a 'green' innovation - the case of organic food. Journal of Marketing Management 28(3-4): 313-333.

Thompson, N. and K. Thompson. 1996. Reasoned action theory: an application to alcohol-free beer. Journal of Marketing Practice: Applied Marketing Science 2(2): 35-48. https://doi.org/10.1108/ eum0000000000020

Tian, X. and X. Yu. 2013. The demand for nutrients in China. Frontiers of Economics in China 8(2): 186206. https://doi.org/10.3868/s060-002-013-0009-9

Tsakiridou, E., C. Boutsouki, Y. Zotos and K. Mattas. 2008. Attitudes and behaviour towards organic products: an exploratory study. International Journal of Retail \& Distribution Management 36: 158-175.

Ureña, F., R. Bernabéu and M. Olmeda. 2008. Women, men and organic food: differences in their attitudes and willingness to pay: a Spanish case study. International Journal of Consumer Studies 32: 18-26.

Willer, H. and J. Lernoud. 2014. The world of organic agriculture statistics and emerging trends 2014. FiBLIFOAM Report. IFOAM - Organics International / FiBL, Bonn / Frick, Germany / Switzerland.

Wirth, F., J. Stanton and J. Wiley. 2011. The relative importance of search versus credence product attributes: organic and locally grown. Agricultural and Resource Economics Review 40: 58-62.

Xia, W. and Y. Zeng. 2007. Consumer's attitudes and willingness-to-pay for Green food in Beijing. Paper presented at the $6^{\text {th }}$ International Conference on Management (ICM). August 3-5, 2007. Science Press, Wuhan, China.

Xia, W. and Y. Zeng. 2008. Consumer's willingness to pay for organic food in the perspective of metaanalysis. Paper presented at: International Conference on Applied Economics, ICOAE, Technological Education Institute of Western Macedonia, Greece, pp. 933-943.

Xie, B., L. Wang, H. Yang, Y. Wang and M. Zhang. 2015. Consumer perceptions and attitudes of organic food products in Eastern China. British Food Journal 117(3): 1105-1121.

Xu, Y., Q. Liang and Z. Huang. 2018. Benefits and pitfalls of social capital for farmer cooperatives: evidence from China. International Food and Agribusiness Management Review 21(8): 1137-1152.

Yang, M., S. Al-Shaaban and T.B. Nguyen. 2014. Consumer attitude and purchase intention towards organic food: a quantitative study of China. MSc-thesis, Linnæus University, Kalmar, Sweden.

Yen, T.F. 2017. Managing self congruity to influence behavioral intention in organic food contexts in Fujian province, China. MATEC Web of Conferences 123. Available at: https://doi.org/10.1051/ matecconf/201712300032

Yin, S., L. Wu, L. Du and M. Chen. 2010. Consumers' purchase intention of organic food in China. Journal of the Science of Food and Agriculture 90(8): 1361-1367. https://doi.org/10.1002/jsfa.3936 
Yiridoe, E., S. Bonti-Ankomah and R. Martin. 2005. Comparison of consumer perceptions and preference toward organic versus conventionally produced foods: a review and update of the literature. Renewable Agriculture and Food Systems 20: 193-205.

Yu, X., Z. Gao and Y. Zeng. 2014. Willingness to pay for the 'Green Food' in China. Food Policy 45: 80-87. https://doi.org/10.1016/j.foodpol.2014.01.003

Zhang, L. and L. Han. 2009. An analysis on consumer perception of safe food and purchase behaviour - a survey on fresh food in Shanghai. Chinese Agricultural Science Bulletin 25(4): 50-54.

Zhong, F. and X. Yi. 2010. Analysis on difference between consumers' concerns and actual purchasing behaviour regarding food safety: case study of vegetable consumption in Nanjing. Journal of Nanjing Agricultural University 10(2).

Zhou, X. 2008. Eating, drinking and sing, and be modern and global: food, karaoke and 'middle class' consumers in China. In: Jaffrelot, C. and P. Van der Veer (eds.) Patterns of middle class consumption in India and China. Sage, New Delhi, India, pp. 170-185.

Zhou, Y.H., L. Huo and X.J. Peng. 2004. Food safety: consumer attitudes, willingness to pay and the impact of information. Chinese Rural Economy 11: 53-59.

Zhu, Y. 2018. Using the theory of planned behavior to investigate what influences Chinese intention to purchase organic food. China-USA Business Review 17(6): 324-333. 
